\title{
BIODIREITO, ANIMAL DE ESTIMAÇ̃̃O E EQUILÍBRIO FAMILIAR: APONTAMENTOS INICIAIS
}

\author{
BIODERECHO, ANIMAL DE MASCOTA Y FAMILIA: NOTAS INICIALES
}

\author{
${ }^{1}$ Tereza Rodrigues Vieira
}

\section{RESUMO}

As discussões acerca da relação do animal com a família têm provocado importantes debates, oportunizando a sustentação de diversos pontos de vista fundamentados em argumentações bioéticas e jurídicas. O objetivo do presente artigo é discutir e refletir, com base em revisão bibliográfica nas áreas da bioética e do direito, acerca da situação jurídica dos animais de estimação em questões ligadas à família e levadas ao Judiciário. Considerando que esses seres vulneráveis são dependentes da ação do ser humano para sua proteção, conclui-se que não é possível justa solução sem a observação do bem-estar animal.

Palavras-chave: Família, Animal, Divórcio

\section{RESUMEN}

Las discusiones acerca de la relación del animal con la familia provocaim portantes debates, dando oportunidad a la sustentación de puntos de vista fundamentados en argumentos bioéticos y jurídicos. El objetivo del artículo es reflexionar, basándonos en una revisión bibliográfica en las áreas de bioética y derecho, acerca de la situación jurídica de los animales de mascota y sus consecuencias en cuestiones ligadas a la familia y el juicio. Considerando que estos seres vulnerables son dependientes de la acción del ser humano para su protección, se concluye que no es posible solución justa sin la observación del bienestar del animal.

Palabras-claves: Familia, Animal, Divorcio

\footnotetext{
${ }^{1} \mathrm{PhD}$ em Direito Université de Montreal, Canadá. Doutora em Direito pela Pontifícia Universidade Católica PUC, São Paulo - SP (Brasil).. Professora da Universidade Paranaense, UNIPAR, Umuarama - Paraná (Brasil). E-mail: terezavieira@uol.com.br
} 


\section{INTRODUÇÃO}

A relação do homem com o animal doméstico vem se ampliando com o passar do tempo, estreitando-se cada dia mais. Assim, não é de se estranhar o amor e apego aos animais de companhia como cães e gatos, por exemplo, que fazem parte do cotidiano de muitas famílias. Considerando essa proximidade, muito se reflete sobre sua contribuição para a qualidade de vida da família e suas implicações jurídicas e bioéticas, justificando um estudo mais detalhado, abarcando o bem-estar animal.

Sucede que, além da responsabilidade sobre os animais domésticos, seus guardiães também veem aspectos positivos sobre o bem-estar da família, sobretudo em termos de sociabilidade e afetividade. Há casais que encontram nos animais de estimação uma relação sui generis de amizade ou filiação.

No Brasil, a ligação do biodireito, animais de estimação e família vem se avigorando com o passar dos anos. Advogados, promotores e juízes não têm se furtado a reivindicar e proclamar direitos oriundos dessa relação, enriquecendo a doutrina e a jurisprudência sobre a matéria.

O mínimo ético a ser respeitado é assinalado pela bioética, mas o direito é quem lhe dá coercibilidade. O bioética serve como norte, guia, fundamento e direção a serem observados, sem, no entanto, haver hierarquia. À estas duas importantes áreas interessa o bemestar animal, estudado aqui sob a ótica do convívio familiar, haja vista que produz importantes repercussões jurídicas.

Não há que se negar a presença e importância do animal de estimação, seja no meio urbano ou rural, com sensibilização dos guardiães para o respeito ao animal. Estes, em geral, frequentam todos os compartimentos da casa, acompanhando o seu guardião em quase todas as atividades, sendo considerado, por vezes, como membro da família.

Assim, o Judiciário já vem recebendo diversas demandas para se pronunciar acerca dessa delicada relação entre casais e animais domésticos, sobretudo cães e gatos. Frise-se desde já que, não se almeja atribuir ao animal o status humano, mas refletir sobre algumas condutas humanas, por vezes, paradoxais, em face dos animais domésticos. 
O objetivo do presente artigo é refletir, ainda que sucintamente, acerca de alguns aspectos bioéticos e jurídicos que circundam a relação do animal de estimação com a família, sobretudo, quando não há consenso, culminando com a contenda judicial. Com base em revisão bibliográfica discorrer-se-á sobre este controverso tema, em apontamentos iniciais, considerando a vastidão do assunto e a falta de legislação específica.

Destarte, o intento maior aqui é convidar à reflexão, mais que dar respostas prontas, conforme se verá a seguir.

\section{REFLEXÕES BIOÉTICAS E JURÍDICAS}

Por tratar-se de um vasto campo que ainda não apresenta legislação específica, a maioria das questões suscitadas não apresenta resposta simples e rápida, pois demanda muita reflexão, dependendo da concepção que cada um tem sobre a importância do animal e sua relação com os humanos.

Indaga-se, por exemplo: Animal tem dono? O proprietário do animal é aquele que compra ou aquele que cuida? No regime de separação de bens pode existir disputa de guarda do animal? É justa a retirada dos filhotes do aconchego da mãe para serem entregues à venda? É possível considerar o animal de estimação como integrante do grupo familiar? Por que algumas pessoas veem os animais como filhos? Qual o critério para se decidir com quem fica o animal no momento do rompimento do casal? Há sofrimento do animal com a separação do casal? A guarda do animal pode ser definitiva? É possível o exercício da guarda compartilhada? De quem é a competência para julgar somente sobre a guarda do animal: Vara Cível ou Vara de Família? É possível aplicação da Arbitragem? É cabível pagamento de Alimentos para o animal de estimação?

E ainda: É possível nomear um tutor ao animal? Em caso de procriação do animal, o cônjuge que não detêm a guarda também terá direito aos filhotes? Na adoção humana não podemos separar os irmãos, mas quanto aos filhotes? Pode o animal de estimação ser penhorado para pagar dívida ou como garantia? Pode o Estatuto da Criança e do Adolescente, subsidiariamente, ser aplicado? Deve existir uma lei especial que tutele os animais 
de companhia ou esses devem ser tratados como os demais? Contribuem os animais para o equilíbrio familiar?

As possíveis respostas aos questionamentos acima, incitam o leitor a imaginar os dilemas éticos e legais pelos quais passam aqueles que detêm em sua companhia um animal durante anos, como um cão ou um gato, considerando que estes estão presentes em quase todos os lares, se relacionando com a família, amigos, vizinhos e, inclusive, com animais de outras espécies que habitam o mesmo ambiente, como pássaros e peixes.

Apesar disso, a legislação brasileira em seu Código Civil (2015), arts. 82 e 1.232, veem os animais e suas crias como móveis, por serem bens suscetíveis de movimento próprio, ou de remoção por força alheia, sem alteração da substância ou da destinação econômico-social. Assim, suas crias pertencem ao seu proprietário, podendo ser vendidas ou doadas. Por sua vez, o art. 225, VIII, da Constituição Federal (2015) proibe a crueldade e coibe as práticas que coloquem em risco sua função ecológica, ou provoquem a sua extinção.

A Lei no $9.605 / 1998$ é quem determina as sanções penais e administrativas decorrentes de condutas e atividades que ferem o meio ambiente, regulando também os crimes contra os animais, inclusive domésticos e domesticados.

\section{NOVAS FAMÍLIAS E ANIMAIS DE ESTIMAÇÃO}

Animais de companhia parecem receber um tratamento especial por parte das pessoas, uma vez que com elas permanecem boa parte do tempo, recebendo peculiar atenção. Cães, gatos, hamsters, coelhos, iguanas etc são considerados animais de companhia, pois permanecem no lar. Há animais que são compreendidos pela legislação especial que impede sua apreensão.

A propósito, ressalta Medeiros, no tocante aos animais de estimação ( 2013, p. 212):

Esses animais, na grande maioria vezes, são tratados como animais humanos, perdendo seu referencial do 'ser'. [...] O número de filhos nas famílias modernas diminuiu e aumentou o número de animais de estimação, paradoxalmente, passou-se a tratar esses animais de estimação como se fossem 'animais-filhos'. 
Estudo realizado pela Associação Psicológica dos Estados Unidos e publicado no Journal of Personality and Social Psychology, demonstrou que conviver com um animal doméstico é um instrumento essencial de suporte social, que aporta inúmeros proveitos físicos e psicológicos. Assim, “descobriu-se, então, que os animais podem compensar algum tipo de rejeição tão bem quanto um melhor amigo humano. Portanto, os pets podem ser grandes amigos em momentos difíceis, ajudando psicológica e fisicamente a seus donos." (DOMINGUES, 2013).

Estabelece a Convenção Europeia dos Direitos dos Animais de Companhia o dever especial do detentor do animal a cuidar, de modo a não colocar em causa os parâmetros de bem-estar, e vigiá-los de modo a evitar que este coloque em risco a vida ou a integridade física de outros animais e pessoas. Assim, caracteriza abandono a não prestação de cuidados no alojamento, ou a sua remoção para fora do domicílio ou dos locais onde habituam estar mantidos, com intuito de pôr fim à sua detenção, sem que passem a sua guarda e responsabilidade para outras pessoas, autarquias locais ou sociedades de animais (LEITE; NASCIMENTO, 2004).

A Convenção Europeia também proíbe a utilização de animais com intuitos didáticos e lúdicos, filmagens, de treino, publicidade, se passível de resultar dor ou sofrimentos consideráveis, exceto experiência científica necessária e justificada pela lei. É proibida a violência contra animais de estimação e o seu bem-estar deve estar salvaguardado em casos de alojamento, reprodução, criação e manutenção. (LEITE; NASCIMENTO, 2004).

Não é despiciendo lembrar aqui que a evolução do conceito de família vem permitindo novos enquadramentos e modelos. Hironaka afirma que,

dizer o que a família "é" para o direito necessariamente requer que fechemos os olhos para um sem-número de fatos sociais essencialmente representativos da família, mas que por vezes não se encaixariam nas letras frias de um invólucro qualquer do Direito positivado. Daí necessidade de que os conceitos sejam cada vez mais abertos, especialmente em matéria de família. (2015, p.53)

Assim, há quem considere os animais de estimação como novos integrantes sui generis da família, pois presentes no contexto familiar cotidiano. Assinala Chaves (2015, p.8):

Há casais que se unem e simplesmente não desejam procriar, não desejam possuir 
descendência humana. Mas "adotam" cachorros, gatos e outros tipos de animais domésticos a quem carinhosamente chamam de "filhos" e tratam como se sua prole fosse. Em seu íntimo, sentem-se exercitando a parentalidade em relação a seres que não são humanos. Estar-se-ia "humanizando" os animais ou "coisificando" as relações humanas? Não nos parece. O fato de os animais a cada dia se tornarem elementos mais importantes dentro do ambiente familiar onde se encontram inseridos não os torna humanos e o reconhecimento da importância das relações entabuladas entre humanos e seus animais de companhia não nos torna coisas e, em última análise, menos dignos.

Sentencia Pastori (2013, apud PIRES; VIEIRA, 2016) que, ter um animal de estimação em casa confere a garantia de um afeto transbordante que remete os humanos a um lugar existencial mais seguro, afinal, eles oferecem uma segurança inexistente em seu mundo. Nesse contexto, vai ao encontro da necessidade do espaço atual das pessoas, ocupado com preocupações infinitas, e no qual o animal passa conforto aos que detêm sua tutoria. Esse excesso de amor dentro das relações homem e animal surpreende na transformação da interpretação de pet, para filho.

Relatórios e pesquisas vem demonstrando que o estereótipo da família brasileira tradicional também tem se transformado, caindo o número de casais com filhos. Constatou- se que cresce a presença de animais de estimação nos lares brasileiros, superando o número de crianças. Referidos dados são corroborados pelo Instituto Brasileiro de Geografia e Estatística (IBGE) obtidos em 2013 e, publicados em 2015. (ARIAS, 2015)

Explana ARIAS, baseando-se os dados colhidos pelo IBGE:

De cada cem famílias, 44 criam, por exemplo, cachorros e só 36 têm crianças até doze anos de idade. Contando os gatos e outros animais o número sobe para cem milhões. Segundo o IBGE, as famílias brasileiras cuidam de 52 milhões de cães contra 45 milhões de crianças. E a tendência indica que haverá cada vez mais espaço nas casas para os animais e menos para os filhos. [...] O mercado em torno dos novos filhos de quatro patas que move, a cada ano, no Brasil a cifra de 16 bilhões de reais. [...] Esse crescimento do interesse das famílias brasileiras pelos animais, a quem se devota muitas vezes um carinho igual aos dirigido às crianças, explica também o interesse cada vez maior dos políticos por aprovar leis a favor de seus direitos, como os cemitérios personalizados, as clínicas veterinárias gratuitas para as famílias menos abastadas, ou uma maior liberdade de movimentos nas cidades para que esses animais possam circular nos meios públicos de transporte. Ou também uma maior permissividade para que os animais possam visitar seus donos nos hospitais. (2015, p.2-4) 
No tocante ao relacionamento interespécie, Thoreau (2013) esclarece que há mais facilidade de o ser humano aproximar-se e criar laços afetivos com um cão ou gato do que com outro humano. Marianna Chaves, recordando estudos de Bogdanoski (2010, p. 208) sugere essa grande ligação com animais de estimação quando, por exemplo, sucede:

a prática de pessoas deixarem heranças substanciais para os seus animais de estimação em seus testamentos ou para alguém sob a condição de cuidarem dos animais; a benção de animais por padres e pastores; a prática de enterrar os animais da família em cemitérios de animais; o crescente número de psicólogos e terapeutas que atendem pacientes em extremo sofrimento, vivenciando o luto pela perda do seu animal de estimação. (2015, p. 31)

Há que se refletir percucientemente sobre a constante mutação moral da sociedade, a qual está ultrapassando barreiras e preferindo relacionar-se com outra espécie.

Vazquez, por sua vez, assinala que:

A história nos apresenta uma sucessão de morais que correspondem às diferentes sociedades que se sucedem no tempo. Mudam os princípios e as normas morais, a concepção daquilo que é bom e daquilo que é mau, bem como do obrigatório e do não obrigatório. (2002, p. 53).

Em decorrência do afeto, evidencia-se que a nova família evolui e abarca também em seus braços animais de estimação, devendo por eles amplamente zelar.

\section{AFETO E CONTEMPLAÇÃO DA BELEZA ANIMAL}

Autores narram inúmeros benefícios trazidos pelos cães em contato com os humanos.

O amor e a devoção dos animais em relação aos seus donos são, por vezes, equiparados ao do bebê pela mãe. Veja-se:

Uma das últimas descobertas científicas, publicadas na prestigiosa revista Science, é que os cachorros amam seus donos com o mesmo amor do bebê por sua mãe. Também afirma-se que conviver com um animal de estimação, olhar sua mascote nos olhos, brincar com ela ou acariciá-la, produz forte dose de oxitocina, chamada de "molécula do amor". Era conhecido que a oxitocina inibe a amídala, a área cerebral encarregada de oferecer respostas ao medo e à agressão. Essa substância, muito presente nos momentos em que nos apaixonamos, também serve para reduzir o medo social. [...] Se nos humanos a carga de oxitocina costuma diminuir com o desgaste das 
relações amorosas, não acontece o mesmo com os animais, que sempre são bebês e consideram seu dono, homem ou mulher, como sua mãe. Por isso, considera-se que o amor que um animal sente por nós é inabalável e de absoluta fidelidade. Eles também estão eternamente apaixonados por nós. Exatamente como um bebê por sua mãe. (ARIEL, 2015, p.5-6)

A simples contemplação dos animais já transmite sensação de alegria e bem-estar, trazendo tranquilidade para o espírito. Assertiva confirmada por Tafalla (2013, p. 73) ao abordar o fascínio estético transmitido pelos animais. Sendo tão diferentes uns dos outros em formas, cores, movimentos e sons, diferentes espécies de animais estimulam os sentidos humanos e despertam a imaginação. Também são admirados porque são seres vivos e agradáveis de serem vistos vivendo suas vidas, atuando, brincando, interagindo uns com os outros, emocionando, e até mesmo reagindo diante do nosso olhar.

Conviver com animais, realizar terapias assistidas com eles ou simplesmente contemplá-los pode contribuir para a melhora da saúde física, mental e emocional. O animal estimula a motricidade e sentidos da criança. Aquários com peixes despertam um pouco de alegria nos pacientes com depressão ou Alzeimer. Contudo, um pássaro, por um descuido, pode até escapar da gaiola, mas o peixe precisa de água. Trocar mar aberto por um aquário minúsculo não parece uma troca justa apenas para exibir aos amigos ou filhos. Não há outro meio para se obter as mesmas sensações, tais como música, sons de chuva ou fonte, imagens ou filmes com animais e plantas?

Interessante aqui se fazer uma analogia da adoção de uma criança e a de um animal. Em vias de se adotar uma criança, o assistente social vai até o lar dos futuros adotantes para verificar se o ambiente em que irá viver é adequado, contudo, o mesmo não acontece com os animais. O Veterinário não é pago para efetuar uma visita com o intento de verificar se são bem alimentados, livres de perigo, condições ideais de temperatura e luz. (TAFALLA, 2013)

No tocante aos cães, por exemplo, são os guardiães que decidem se devem ou não cruzar. Aos humanos perguntamos se querem ou não adotar filhos, mas ao animal não the é investigado se prefere viver com humanos ou com seus semelhantes.

Animais domesticados estão hoje adaptados ao convívio com humanos, com quem trocam afeto. Contudo, como não se pode trancafiar os filhos dentro de casa, sem brincar, correr ou passear, aos animais domésticos devem ser franqueados os mesmos direitos. Para ser 
contemplado por humanos, retirou-se o animal do seu meio natural e foi-lhe dado em troca um meio artificial, diferente do seu mundo.

A beleza animal encanta, seja por sua formusura, imponência, cores, elegância, inteligência, fidelidade etc. Tafalla (2013, p. 85) defende que o valor estético dos animais constitui uma boa razão em favor da biodiversidade, como em geral o valor estético da natureza é uma das melhores razões que justificam sua proteção. Por vezes, a mesma pessoa que maltrata o animal, o faz enquanto dirige palavras de apreço e se maravilha com sua beleza.

A relação que mais interessa no presente estudo é a troca de companhia e afeto entre a família e o animal de estimação. No dizer de Arthur Shopenhauer, prende-se em um metro cúbico um pássaro que está planejado para atravessar o mundo voando e, alí preso, lentamente deseja a morte e grita, pois o pássaro na jaula não canta de prazer, mas de raiva. (Apud Tafalla, 2013, p.88)

Diante de tanto encanto, muitos se animam a desfrutar de tamanha beleza em seu próprio lar, adquirindo o animal, aprisionando-o entre quatro paredes ou em aquários, criando mais uma importante questão ética a ser debatida. Como separar a admiração do desejo de domínio? Quando se aprisiona, está se protegendo ou maltratando o animal? Que sentimento é este transmitido aos filhos que leva ao aprisionamento do animal? É uma boa lição ética a ser-lhes deixada? Será que uma boa lição para deixar ao filhos não seria alimentar, proteger, dar atenção veterinária para sobreviver mais tempo, sem aprisionar? (TAFALLA, 2013, p. 73)

Importante jamais olvidar que o fascínio não deve levar à perda da liberdade animal.

Sobre o animal de estimação na família, pode-se revelar que é um paciente confidente, sensível aos estados emocionais. Diz-se que:

Ele facilita a comunicação entre os membros da família de todas as gerações. Ele não julga, às vezes age como um substituto quando um parceiro não está disponível. O animal também arbitra os problemas do casal. Ele pode "aliviar" atritos, desviando a atenção para si mesmo. Finalmente, é um excelente barômetro do nível de ansiedade e tensão do grupo familiar. Como é que ele pode dar um apoio análogo ao isentar certos membros da família? Ao fornecer seu afeto livremente, facilita a comunicação e reduz o estresse através do seu incentivo para brincar e atividades recreativas. No entanto, é importante que o animal não se torne o problema de conflito famíliar: as responsabilidades de cada um devem ser claramente distribuídas e fixadas. Isso nem sempre dá errado quando há dissolução da família (divórcio ou separação) onde vemos mais e mais vezes o animal tornar-se objeto de um acordo entre as partes (custódia e / ou visite). (ETHO NEWS, 2001, p.1) 
Assim, a família se preocupa em melhorar a qualidade de vida dos seus componentes, independentemente da idade e encontra no animal um companheiro ideal.

\section{REPERCUSSÕES JURÍDICAS}

Confirmando o asseverado no tópico anterior, de acordo com estudo realizado no Canadá, cerca de $90 \%$ dos canadenses conversam com seus cães, e 53\% confiam mais neles do que em humanos, e as crianças também confiam mais nos cães do que em seus pais. Conclui também a pesquisa que os cães, após o divórcio, sofrem de ansiedade e depressão. (EQUIPE, 2014)

Muitas podem ser as consequências provocadas pelo rompimento do casamento ou união estável cujo lar integra um animal de estimação, as quais podem atingir os guardiães, os animais ou ambos.

Com a dissolução do casamento através do divórcio, em não havendo consenso, é possível que o casal dispute a guarda e direito de visita do animal de estimação. Indaga-se: Será que o animal deve ficar com o proprietário ou com quem possui mais aptidão para dele cuidar?

A regra indica que o proprietário é quem ficará com o animal, contudo, o Judiciário já vem decidindo pela guarda compartilhada, vez que não são simples objetos. No tocante a guarda compartilhada, esta apresenta dificuldades, caso um dos ex-cônjuges se mude para local distante.

Lembram Eithne e Akers que:

se o animal de estimação é do tipo que será severamente afligido pela constante mudança, não é no melhor interesse do animal de estimação ser objeto de um pedido de guarda compartilhada entre os dois proprietários, e embora seja no melhor interesse do parceiro que não possui a guarda ter pelo menos visitas freqüentes e regulares ao animal de estimação, isso pode não ser financeiramente ou logisticamente possível. (2011, p.231)

Na acepção de Camilo Henrique Silva, no que se refere às questões de divórcio, abrangendo a guarda de animais de estimação, o magistrado "deve promover um verdadeiro debate para chegar ao melhor resultado para o animal de estimação, independente da 
vontade dos postulantes à tutela, pois somente assim, o direito desses seres vulneráveis será respeitado e garantido." (2015, p. 113)

Em casos que envolva a adoção de pessoas, aplica-se o Código Civil e o Estatuto da Criança e do Adolescente. Em casos de animais de estimação, mutatis mutandis, poder- se-ía aplicar, analogicamente, a guarda compartilhada ou alternada no intuito de amenizar os efeitos danosos causados com a ruptura do casal. É possível que, no pacto antinupcial os cônjuges estabeleçam quanto à guarda dos animais e direito à visitas.

Reza o artigo 1.589 do Código Civil, ao estabelecer que o "pai ou a mãe, em cuja guarda não estejam os filhos, poderá visitá-los e tê-los em sua companhia, segundo o que acordar com o outro cônjuge, ou for fixado pelo juiz" (BRASIL, 2016). Contudo, no julgamento do feito, deverá o juiz observar sempre o bem-estar do animal.

A título de ilustração, o cantor Paul McDonald e atriz Nikki Reed, com divórcio formalizado em Março de 2014, decidiu em 2015 que Enzo, um pastor alemão do casal, ficaria com Reed, embora ambos estimassem a companhia do animal. (HARRISON; ROSENBAUM, 2015)

No tocante aos Alimentos, assevera Silva: “ Ao Poder Judiciário cabe impor o dever de alimentar ao tutor não contribuinte, estipulando o valor da pensão de acordo com as necessidades do animal-alimentando e a possibilidade de pagamento do tutor- alimentante". (2015, p.109) Assim, não há basta considerar o simples desejo das partes ou o título de propriedade.

Em São Paulo, o Tribunal de Justiça já teve oportunidade de julgar caso de pensão alimentícia para um animal. A ex-esposa, que havia ficado com a guarda de dois cães após a separação, ingressou com pedido de pensão em face do ex-marido para os animais. A $1^{a}$ Câmara de Direito Privado de São Paulo acatou a solicitação de R\$ 250,00 de pensão alimentícia para cada cachorro até o falecimento. (BARBOSA, 2014)

No entender de Chaves, "nada impede que o magistrado, além do direito de convivência, estipule que o pagamento de alimentos ao animal, de preferência in natura, já que em regra, pets se alimentam única e exclusivamente à base de ração.” (2015, p. 20)

Assim, o melhor guardião é aquele que demonstra mais afeto pelo animal, disponibiliza tempo e zelo. É possível até que o animal venha a ser entregue a um terceiro, 
parente do casal. Em todos os casos, os alimentos devem ser prestados por ambos os cônjuges. No dizer de Marianna Chaves:

Verificado que o animal não deve permanecer com nenhuma das duas pessoas que o criaram e pleiteiam a sua custódia em juízo, o magistrado deverá verificar se há alguma pessoa que também tenha convivido com o pet e que deseje responsabilizarse por ele. (2015, p. 19)

No tocante à competência, a Vara da Família parece ser a mais competente para solucionar os casos de disputa por animais de estimação em juízo, considerando assim o afeto que envolve a relação animal-família. Não é outro o entendimento de Marianna Chaves:

As varas de família, diante da percepção pós-moderna do conceito de família, ao lado da evolução do status legal dos animais de companhia, podem resolver as contendas com base no melhor interesse do ser não humano ou animal, em clara referência ao melhor interesse da criança, harmonizado com o melhor interesse dos humanos" (2015, p.15)

Entende-se ser possível a Arbitragem, vez que " na impossibilidade de autocomposição, um árbitro especializado na matéria certamente estará mais preparado que um juiz. O recurso aos tribunais deverá ocorrer em ultima ratio.” (CHAVES, 2015, p.23)

Há estados, nos Estados Unidos, por exemplo, que referido tipo de litígio pode tramitar em varas especializadas denominadas pet courts. (CHAVES, 2015, p. 31)

Considerando o bem-estar animal, por vezes, o pet de estimação acompanha o casal ou apenas um deles. No Brasil, a Instrução Normativa MAPA no 54/2013 gerou o uso de Passaporte para o Trânsito de Gatos e Cães em viagens internacionais, com validade vitalícia, abrangendo dados zoosanitários essenciais para entrada e saída dos animais nos países integrantes do Mercosul (Argentina, Paraguai, Uruguai e Venezuela). A identificação eletrônica é feita por meio de um microchip introduzido no animal.

Cumpre mencionar aqui a discussão atinente à penhora, se esta poderá ou não ocorrer em relação ao animal de estimação, como forma de coação ao pagamento pelo devedor. Em decorrência do afeto em relação ao animal, o credor aposta no imediato pagamento.

O Superior Tribunal de Justiça (STJ) tem estendido o entendimento acerca da penhora do bem de família, resguardando a acepção ampla da entidade familiar. Em recurso junto ao STJ, que teve como relator o ministro Villas Bôas Cueva, da Terceira Turma, entendeu 
que: "O conceito de entidade familiar deve ser entendido à luz das alterações sociais que atingiram o direito de família". (STJ, 2013, p.1) Aqui poder-se-ía incluir o animal de estimação que tem estreitos vínculos de afeto com a família, ademais, trata-se de um ser vulnerável que demanda proteção.

A propósito, na França o Código Civil prevê alguns dispositivos acerca da responsabilidade parental, guarda e pensão alimentícia, sem aludir aos animais de estimação. Dispõe o art. 528 deste diploma legal, que o cão, o gato, o peixinho etc, são propriedades pessoais. No entanto, alguns magistrados vêm inovando e conferindo direito de visita e guarda dos animais de estimação fora do quadro legal. (Tribunal de Cassação, 2013)

$\mathrm{Na}$ Alemanha, o Código Civil (BGB - Bürgerliches GesetzBuch) não mais considera os animais como coisas em seu § 90a, passando a protegê-los com leis especiais. Quando não houver estabelecido de outra maneira haverá aplicação de forma análoga à coisa. Veja-se o disposto no art. 20a:

Consciente de sua responsabilidade também frente às gerações futuras, o Estado protegerá os recursos naturais vitais e os animais, no âmbito da ordem constitucional, por intermédio do Poder Legislativo e, no campo da lei e do direito, por meio dos Poderes Executivo e Judiciário. (LEVAI, 2007, p. 234).

Ao se mencionar "bases naturais da vida" em lugar de apenas "vida humana" se demonstra que a Lei Fundamental não é meramente antropocentrista.

Conclui-se que casais e animais não possuem relação de filiação ou parentesco. Sucede que ter a guarda de um animal de estimação implica em responsabilidades, por tratar-se de seres sensíveis e vulneráveis. O dever de cuidado é permanente por parte dos humanos.

\section{CONSIDERAÇÕES FINAIS}

A sociedade humana evolui a cada dia e essa transformação passa pela desconsideração do animal de estimação como coisa, reconhecendo não apenas proteção contra abusos e crueldade, mas também a preocupação com o seu bem-estar. 
Evidentemente, dar-se ao pet tratamento similar ao de um membro da família é algo que tem merecido críticas de diversos setores, familiares ou de entidades assistenciais. Isto, muitas vezes, é evidenciado quando ocorre a disputa pela guarda do animal de estimação após o rompimento do casal.

Não se objetivou aqui reconhecer aos animais de estimação o status de pessoa humana, mas de demonstrar que estes não são como coisas inanimadas, como pretendem os defensores de corrente tradicional. Diferentemente de um carro, o animal não é uma mera coisa que se move.

Hodiernamente, a tendência é considerar o animal de estimação uma categoria sui generis em decorrência da senciência e interação com os humanos, merecendo seja o seu conforto observado. Destarte, é possível demandar-se em juízo a guarda, o direito de visita e pensão alimentícia em decorrência da falta de consenso do casal em caso de rompimento da união. Deverá o Juiz ou o Árbitro considerar o bem-estar do animal, e não o título de propriedade de um dos cônjuges.

Os filhos devem ser educados, na escola e no lar, aprendendo a respeitar o animal cuja guarda e responsabilidade cabe a todos. Há que se educar para o respeito aos animais, os quais não devem ter donos, mas guardiães e devem ser livres da exploração ou aprisionamento. Não há necessidade de viver enjaulado para ser contemplado. O desejo do domínio não deve prevalecer sobre o direito a apreciação da beleza externa e interna, considerada integralmente.

Não é justa a retirada dos filhotes do aconchego da mãe para serem entregues à venda para membros de outra espécie. Aqueles que consideram o animal de estimação como integrante do grupo familiar humano olvidam que desintegraram um grupo familiar animal.

Depois de acostumar-se com o casal, e diante da falta de autonomia, é evidente que há sofrimento do animal e vice-versa com a separação. A concessão da guarda do animal não precisa ser definitiva, podendo ser compartilhada ou até alternada. É possível, inclusive, a disputa pela guarda do animal de estimação entre cônjuges casados sob o regime de separação de bens.

Em caso de procriação do animal, o cônjuge que não detém a guarda também terá direito aos filhotes. Contudo, o animal de estimação não pode ser penhorado para pagar dívida ou como garantia, vez que não se trata de um coisa qualquer. 
O Estatuto da Criança e do Adolescente, subsidiariamente, pode ser aplicado, contudo, é importante que se legifere com o intuito de se proteger os animais de companhia, uma vez que contribuem para o equilíbrio familiar.

Não se trata de simples objetos que se movem, mas de vidas que se relacionam com membros de outras espécies.

O Direito e a bioética devem dar-se as mãos e avançar em uma luta multidisciplinar com o ideal de proteger os animais sem destruí-los com o fascínio e egoísmo humanos. Admirar sem sentir-se dono, mas guardião. Admirar sem causar dor ou sofrimento, agindo segundo o melhor interesse do animal.

\section{REFERÊNCIAS}

ARIAS, J. Lares brasileiros já têm mais animais que crianças. El Pais. Publicado em 10.jun.2015. Disponível em: <http://brasil.elpais.com/brasil/2015/06/09/opinion/1433885904_043289.html - . Acesso em: 30.mar.2016

BARBOSA, R. Separação faz casais irem à Justiça por guarda e pensão de animais de estimação. UOL, São Paulo, 05 julho 2013. Disponível em: <http://noticias.uol.com.br/cotidiano/ultimas-noticias/2013/07/05/separacao-faz-casaisirem-a-justica-por-guarda-e-pensao-de-animais-de-estimacao.htm>. Acesso em: 15 jan. 2014.

BOGDANOSKI, T. Towards an Animal-Friendly Family Law: Recognising the Welfare of Family Law's Forgotten Family Members. Griffith Law Review, Vol. 19, n. 2, pp. 197-237, 2010.

BRASIL. Código Civil. Lei $\mathbf{n}^{\circ} \mathbf{1 0 . 4 0 6}$, de 10 de janeiro de 2002 . Vade Mecum. São Paulo: Saraiva, 2015.

BRASIL. Constituição Federal de 1988. Vade Mecum. São Paulo: Saraiva, 2015. BRASIL. Lei $\mathbf{N}^{\circ}$ 9.605, de 12 de fevereiro de 1998. Dispõe sobre as sanções penais e administrativas derivadas de condutas e atividades lesivas ao meio ambiente, e dá outras providências. Publicado no DOU de 13.2.1998, retificado em 17.2.1998

CHAVES, M. Disputa de guarda de animais de companhia em sede de divórcio e dissolução de união estável: reconhecimento da família multiespécie? Disponível em: < http://ibdfam.org.br/artigos/1052/Disputa+de+guarda+de+animais+de+companhia+em+sede +de+divorcio.> Acesso em: 28.jul.2015. 
DOMINGUES, A. Animais de estimação ajudam donos a enfrentarem momentos difíceis. Petrede, 05. Set. 2013.

EITHNE, M.; AKERS, K. Quem fica com os gatos... Você ou eu? Análise sobre a guarda e o direito de visita. Questões relativas aos animais de estimação após o divórcio ou a separação. Revista Brasileira de Direito Animal. Coord. Heron José de Santana Gordilho. Vol.9, jul-dez. 2011, p. 209-240.

EQUIPE, Linkanimal. Como o divórcio afeta o cachorro. Linkanimal, 16 de Jul. de 2014. Disponível em: <http://www.linkanimal.com.br/cachorros/como-o-divorcio-afeta-o- cachorro/ >. Acesso em: 24 ago. 2014.

HARRISON, Lily; ROSENBAUM, Claudia. Disponível em:< http://www.eonline.com/news/610862/nikki-reed-and-paul-mcdonald-s-divorce-finalizedactress-gets-3-homes-cars-and-the-couple-s-dog > Acesso em: 31.Jul.2015.

HIRONAKA, G.M.F.N. O conceito de família e sua organização jurídica. Tratado de direito das famílias. Rodrigo da Cunha Pereira (Org). Belo Horizonte: IBDFam, 2015.

La relation Homme-Animal: De la recherche fondamentale aux expériences pratiques, en passant par le vécu de chacun : une longue histoire pleine d'enseignements. Etho News, n. 107, maio de 2001.

LEITE, F. C.; NASCIMENTO, E. Regime Jurídico dos animais de companhia. Coimbra: Almedina, 2004.

LEVAI, L. F. A condição-animal em Kaspar Hauser: Crítica à ética racionalista: O bom selvagem e a esterilidade da razão. Revista Brasileira de Direito Animal. a. 2, n. 3, jul./dez. 2007. Salvador: Evolução, 2007, p. 209-237.

PASTORI, E. O. Perto e longe do coração selvagem: um estudo antropológico sobre os animais de estimação em Porto Alegre, Rio Grande do Sul. 2012. 106 f. Dissertação (Mestrado)- Universidade Federal do Rio Grande do Sul, Porto Alegre, 2012. Disponível em:<http://www.lume.ufrgs.br/handle/10183/71932>. Acesso em: 27 jul. 2013.

PIRES, L.C.B; VIEIRA, T.R. O animal de estimação é um integrante da família? Animais: Bioética e Direito. Brasília: Consulex, 2016.

SILVA, C.H. Animais, Divórcio e Consequências Jurídicas. Revista Internacional Interdisciplinar INTERthesis, Florianópolis, v.12, n.1, p.102-116, Jan-Jun. 2015. 
STJ amplia bens de família que não podem ser penhorados. Estadão, São Paulo, 28 maio.2013, Conteúdo. Disponível em: < http://www.estadao.com.br/noticias/geral,stj- ampliaimpenhorabilidade-do-bem-de-familia,1036481 > Acesso em: 02 abr. 2016.

TAFALLA, M. La apreciación estética de los animales. Consideraciones estéticas y éticas. Revista de Bioética y Derecho, núm. 28, mayo 2013, p. 72-90.

THOREAU, H. D. A desobediência civil. Universidade Federal do Rio Grande do Sul, Porto Alegre, 1997. 13 f. Disponível em: http://www.ufrgs.br/cdrom/thoreau/thoreau.pdf >. Acesso em: 25 de jul. de 2013.

Tribunal de Cassação. Cass.1ère civ, 20 de novembro de 2013, apel. No .: 12-29174. VAZQUEZ, A. S. Ética. Tradução de João Dell'Anna. 22. ed. Rio de Janeiro: Civilização Brasileira, 2002. 